\title{
DETERMINACIÓN DE LA HORA MITÓTICA DE Guadua angustifolia var. grandicaula (FAMILIA: GRAMINEAE) A PARTIR DE MERISTEMOS RADICULARES
}

\section{DETERMINATION OF TIME MITOTIC OF guadua angustifolia var. Grandicaula (FAMILY: GRAMINEAE) FROM ROOTS MERISTEM}

\author{
${ }^{1}$ Lorena Burbano, ${ }^{2}$ Esmeralda Fernández, ${ }^{3}$ Estefanny Cortés \\ Programa de biología, facultad de ciencias básicas y tecnológicas, Universidad del Quindío \\ ${ }^{1}$ Iorenadelpilarb@gmail.com, ${ }^{2}$ inuyasha.0403@hotmail.com, ${ }^{3}$ gecfuq5@gmail.com \\ Recibido: Agosto 29 de 2010 \\ Aceptado Febrero 23 de 2011
}

\section{RESUMEN}

La especie de guadua G. angustifolia es la más abundante en el neotrópico, con variedades como G. angustifolia var. grandicaula, la cual posee una amplia distribución, siendo de gran importancia por su valor económico, social, cultural y científico. Debido a tal importancia se llevó a cabo el cálculo de la hora mitótica, con el fin de analizar su comportamiento mitótico durante 24 horas, esto se realizó a partir de meristemos radiculares obtenidos de chusquines, los cuales se hidrolizaron con HCL al $5 \mathrm{~N}$ y se tincionaron con orceína acética al $1 \%$, encontrándose que los picos más altos se presentaron a las 8:30, 15:30 y 16:30; presumimos que dicho comportamiento tiene relación con el tipo de metabolismo de estas plantas.

PALABRAS CLAVE: G. angustifolia var. grandicaula, hora mitótica, chusquin, meristemo radicular.

\begin{abstract}
The bamboo species $G$. angustifolia is the most abundant in the neotropics, with varieties such as $G$. angustifolia var. grandicaula which has a wide distribution, being of great importance for their economic, social, cultural and scientific value. Due to the importance of this species, a technique was used to determine the mitotic hour in order to analyze their mitotic behavior for 24 hours. This was made from root meristems obtained from chusquines, which were hydrolyzed with $5 \mathrm{~N} \mathrm{HCl}$ and stained with $1 \%$ acetic orcein, finding that the highest peaks occur in the morning hours at 8:30 and afternoon at 15:30 and 16:30; it is assumed that such behavior is related to the rate of metabolism these plants have.
\end{abstract}

Keywords: G. angustifolia var. grandicaula, mitotic hour, chusquin, root meristem.

\section{INTRODUCCIÓN}

La guadua es una planta forestal, perteneciente a las gramíneas, de las cuales sus especies son de talla más grande dentro de esta familia, y más variadas entre los bambúes. Presentando un tallo ancho, largo y erecto hasta alcanzar varios metros de altura; su reproducción es casi siempre vegetativa ya que sus periodos de floración se llevan a cabo cada muchos años (Murray \& Nabors., 2006).
Los guaduales abarcan gran parte de la formación vegetal del norte de Suramérica, de los cuales la especie G. angustifolia (Kunt, 1822) es la más dominante. Esta especie crece óptimamente en un rango altitudinal de $0-1800 \mathrm{~m}$ de altitud, con temperaturas que varían desde los $17-24 \% \mathrm{C}$, siendo comúnmente encontrados en las orillas de los ríos. En Colombia los guaduales están concentrados en la región andina donde los bosque nativos han sido altamente intervenidos Ilevándolos a una parcial destrucción, por ello han tomado un papel 
importante en cuanto al refugio que ofrece a especies de animales como mamíferos, aves nativas y migratorias, una gran cantidad de invertebrados, y además gran diversidad de flora que está comúnmente asociada a ellos (Judziewicz et al.,1999).

La guadua es también de gran importancia económica por su implementación en construcciones, debido a la disminución de costos y la gran diversidad y belleza de productos que se puede conseguir a partir de ésta (Giraldo \& Sabogal., 2005); es por tanto que los estudios citogenéticos podrían contribuir a la actual necesidad de obtener un producto tanto ecológica como morfológicamente de mejor calidad. Además, los estudios de citogenética pueden ser la base de proyectos para el mejoramiento y plantear estrategias de conservación in situ y ex situ (Palomino et al., 2005).

El ciclo celular es el mecanismo universal de reproducción de las células eucariontes, cuyo evento principal es la reproducción del número de cromosomas, siendo la mitosis el mecanismo de división de los cromosomas, del núcleo y de toda la célula. El ciclo celular completo (regular) del organismo en crecimiento comprende dos etapas: 1. la interfase (prolongada) y 2. La mitosis (de $1 / 7$ a $1 / 10$ de todo el ciclo celular), y consta de cuatro fases: profase, metafase, anafase y telofase. Durante la interfase es posible observar un período $\mathrm{S}$ (síntesis) y dos periodos G, G1 (anterior a S) y G2 (posterior a S). Durante el periodo comprendido entre la telofase y la fase $S$, los núcleos presentan la cantidad de material genético propio de la especie (2n). Durante la fase $S$ esta cantidad aumenta paulatinamente y a partir del período G2, hasta la siguiente telofase es el doble. Sin embargo, el ciclo celular no siempre termina con la división celular. Los periodos G1 y G2 no son sólo espacios de transición al período $S$ y a la mitosis, sino también son espacios de decisión sobre si la célula continúa o no en el ciclo de la división o si se separa temporalmente o definitivamente de él. (Talledo \& Escobar., 1995),

Estudiar el ciclo mitótico de una especie es de gran importancia para estudios como:

- Variabilidad respecto al número, tamaño y forma de los cromosomas de las especies de este grupo.

- Evidenciar cromosomas mitóticos, especialmente metafásicos.

- Alteración de las características de las muestras originales del germoplasma introducido para su reproducción in vitro y la insuficiencia de los métodos utilizados en la evaluación de su estabilidad genética. (Talledo \& Escobar., 1995).

El ciclo celular es indispensable en la citogenética, debido a que esta permite:

- Utilizar criterios adicionales para la clasificación taxonómica y filogenética de las especies.

- Aclarar una serie de problemas evolutivos (tanto generales como referidos al origen de determinados grupos).

- Predecir el comportamiento de las muestras en los bancos de cultivos in vitro (Talledo et al.,., 1993)

El objetivo principal de este estudio fue encontrar el comportamiento mitótico de la G. angustifolia var. grandicaula en las 24 horas del día, teniendo como objetivo específico el estandarizar el protocolo adecuado para obtener resultados óptimos.

\section{MATERIALES Y MÉTODOS}

1. Material biológico: se extrajo 15 chusquines (plántulas con raíces unidas al rizoma madre) a partir de plantas de la reserva natural "El 
Ocaso" Quimbaya, Quindío; los cuales fueron lavados con detergente en polvo (para desinfectar), el 11 de septiembre de 2009 fueron sembrados en medio Murashige y Skoog (1962) en substrato vermiculita (la cual fue esterilizada previamente), con el propósito de inducir el brote de partes vegetativas y su adaptación a las condiciones de invernadero, donde se las regó con agua destilada cada ocho días. La siembra se realizó en frascos de vidrio cubriendo la boquilla con papel aluminio. Al cabo de 60 días se realizó un conteo de ápices radiculares, tomándose en cuenta sólo los que se ajustaban a las condiciones necesarias para hora mitótica, es decir con una coloración blanca, de aspecto brillante y consistencia frágil.

\section{Determinación de índice mitótico:}

2.1 Fijación: Una vez se obtuvo la suficiente cantidad de ápices, fueron cortados (aproximadamente de $0,5 \mathrm{~cm}$ de longitud) y fijados en carnoy ( 3 partes de etanol: 1 parte de ácido acético) alrededor de dos ápices cada hora durante 24 horas, donde permanecieron como mínimo 24 horas antes de ser procesados a una de temperatura de $0 \stackrel{\circ}{ } \mathrm{C}$.

2.2 Coloración: los ápices de cada muestra se cortaron de tal manera que sólo quedó el meristemo, los cuales fueron macerados sobre un portaobjetos, a estos se les adicionó ácido clorhídrico al 5N durante 10 minutos, luego se lavaron con agua destilada para poner una gota de orceína acética al $1 \%$ durante 20 minutos, dejándose actuar en un sitio oscuro para evitar la fotolisis del colorante.

2.3 Squash: se retiró el exceso de colorante con papel absorbente para poder colocar el cubreobjetos, luego se flameo alrededor de 10 veces sin dejar que hirviera el colorante, $y$ con un hisopo se golpeo para realizar el extendido.
2.4 Conteo de células: la muestra fue observada al microscopio óptico marca Leica utilizando como máximo objetivo el de 100X, contando 100 células y determinado de cada una de ellas la fase en que se encontraban.

2.5 Procesamiento de datos: a partir del conteo de células se determinó, con base en lo planteado por Talledo \& Escobar (1995), el índice de fases (IF) parcial que representa el porcentaje de células que se encontraba para cada fase, y la sumatoria de las que se encontraban en división, es decir omitiendo las interfases, lo que se denomina índice de mitótico (IM) parcial. Para encontrar estos valores se aplicaron las siguientes fórmulas:

- Índice de fases:

$$
\text { IF }(\%)=\frac{\text { № de cédulas de cada fase }}{\text { № total de cédulas }} \times 100
$$

- Índice mitótico:

$$
\text { IM }(\%)=\text { Ifp + IFm + IFa + IFt }
$$

Además, se calculó el índice de fases (IF) total también en porcentaje, lo que se obtiene sumando los IF parciales y esto dividido entre el número de horas, además con la suma de estos valores se obtiene el índice mitótico (IM) total; a continuación se muestran las fórmulas utilizadas:

- Índice de fases:

$$
\text { IF total }(\%)=\frac{\text { IF \% parcial de cada fase }}{\text { № de horas }}
$$

- Índice mitótico:

$I \mathrm{M}_{\text {total }}(\%)=I f p_{\text {total }}+I F m_{\text {total }}+I F a_{\text {total }}+$ IFt total

Donde; IF: índice de fases, IM: índice mitótico, p: profase, $\mathrm{m}$ : metafase, a: anafase, t: telofase.

También se halló la duración total del ciclo celular (CC) dividiendo el IF total para cada fase entre el número de horas (24) durante las cuales se tomaron las muestras. 


\section{RESULTADOS}

Material biológico: De los 15 chusquines sembrados se adaptaron 11 exitosamente a las condiciones de invernadero respondiendo adecuadamente al medio Murashige y Skoog (1962) y resistiendo a infecciones por hongos e invasión de algas. En el conteo de ápices se encontró un promedio de tres ápices (adecuados) por plántula.

Determinación de índice mitótico: con los resultados obtenidos (tabla 1) se pudo observar que el porcentaje del IF total de las profases fue el más alto con un valor de $41.42 \%$, lo que lleva a que la duración en horas de células en profase sea de 1.72 .

Además, el porcentaje de IF total de anafases fue el más bajo del ciclo celular con un valor de $3.83 \%$ (tabla 1) lo que conlleva a una baja duración en las horas del día para esta fase siendo de 0.16 horas.

De la misma manera, se encontró que el porcentaje de división celular (IM total) es de 97.16\% (tabla 1), siendo este un porcentaje muy alto en el que la planta está en su mayor parte del ciclo celular en división.

Tabla 1. Porcentajes sobre 100 células de cada fase (IF parcial e IF total), se muestra también el IM parcial y el total.

\begin{tabular}{ccccccc}
\hline Hora & Interfase IF (\%) & $\begin{array}{c}\text { Profase IF } \\
(\%)\end{array}$ & $\begin{array}{c}\text { Metafase IF } \\
(\%)\end{array}$ & $\begin{array}{c}\text { Anafase IF } \\
(\%)\end{array}$ & $\begin{array}{c}\text { Telofase IF } \\
\text { (\%) }\end{array}$ & IM (\%) \\
\hline $00: 30$ & 41 & 41 & 7 & 5 & 6 & 59 \\
$01: 30$ & 36 & 34 & 9 & 3 & 18 & 64 \\
$02: 30$ & 38 & 43 & 5 & 12 & 2 & 62 \\
$03: 30$ & 44 & 43 & 7 & 2 & 4 & 56 \\
$04: 30$ & 53 & 40 & 5 & 1 & 1 & 47 \\
$05: 30$ & 41 & 58 & 1 & 0 & 0 & 59 \\
$06: 30$ & 47 & 33 & 9 & 4 & 7 & 53 \\
$07: 30$ & 32 & 31 & 17 & 3 & 17 & 68 \\
$08: 30$ & 23 & 38 & 20 & 11 & 8 & 77 \\
$09: 30$ & 32 & 47 & 13 & 0 & 8 & 68 \\
$10: 30$ & 32 & 53 & 8 & 1 & 6 & 68 \\
$11: 30$ & 34 & 45 & 7 & 1 & 13 & 66 \\
$12: 30$ & 30 & 41 & 14 & 7 & 8 & 70 \\
$13: 30$ & 38 & 45 & 5 & 3 & 9 & 62 \\
$14: 30$ & 16 & 61 & 6 & 1 & 16 & 84 \\
$15: 30$ & 18 & 70 & 6 & 0 & 6 & 82 \\
$16: 30$ & 17 & 58 & 13 & 2 & 10 & 83 \\
$17: 30$ & 52 & 37 & 2 & 3 & 6 & 48 \\
$18: 30$ & 54 & 22 & 10 & 2 & 12 & 46 \\
$19: 30$ & 50 & 28 & 5 & 12 & 5 & 50 \\
$20: 30$ & 51 & 31 & 10 & 4 & 4 & 49 \\
$21: 30$ & 31 & 29 & 9 & 3 & 8 & 49 \\
$22: 30$ & 49 & 34 & 9 & 5 & 3 & 51 \\
$23: 30$ & 48 & 32 & 9 & 7 & 4 & 52 \\
IF (\%) & 35.79 & 41.42 & 8.58 & 3.83 & 7.54 & \\
CC & 1.49 & 1.72 & 0.35 & 0.16 & 0.31 & \\
\hline
\end{tabular}


Otro aspecto importante encontrado es que la duración total del ciclo celular es de 4.03 horas (tabla 1), presentando picos irregulares de porcentaje de división celular durante todo el día.

Se encontró también que las fijaciones de las horas $8: 30,15: 30$ y $16: 30$ muestran un alto porcentaje de división celular, pues a estas horas se encuentran los picos más altos de la curva (figura 1 ) del IM parcial, lo cual representa que las células se encuentran a estas horas con un alto número de profases y metafases.

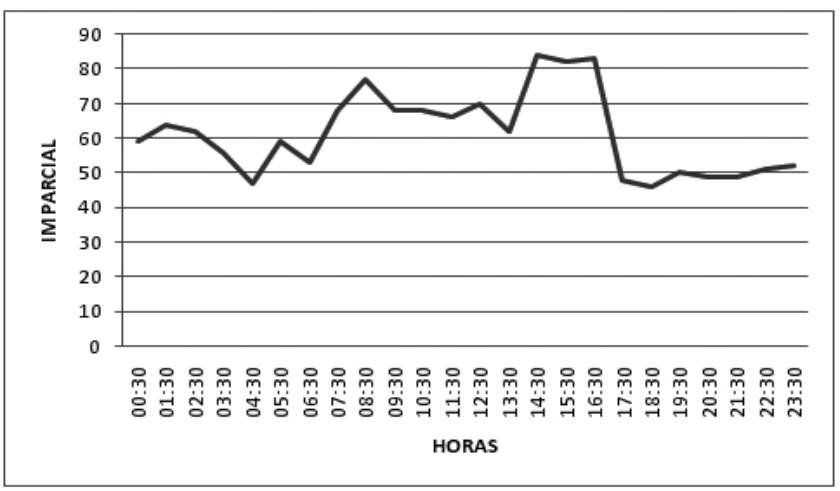

figura1. Ciclo celular de G. angustifolia var. grandicaula donde se relaciona el IM (índice mitótico imparcial) con el número de horas.

Con la observación de las muestras procesadas para conteo de fases se encontró células que estaban en metafase temprana en las que se pudo observar que los cromosomas de las especie son pequeños y abundantes (figura 2).

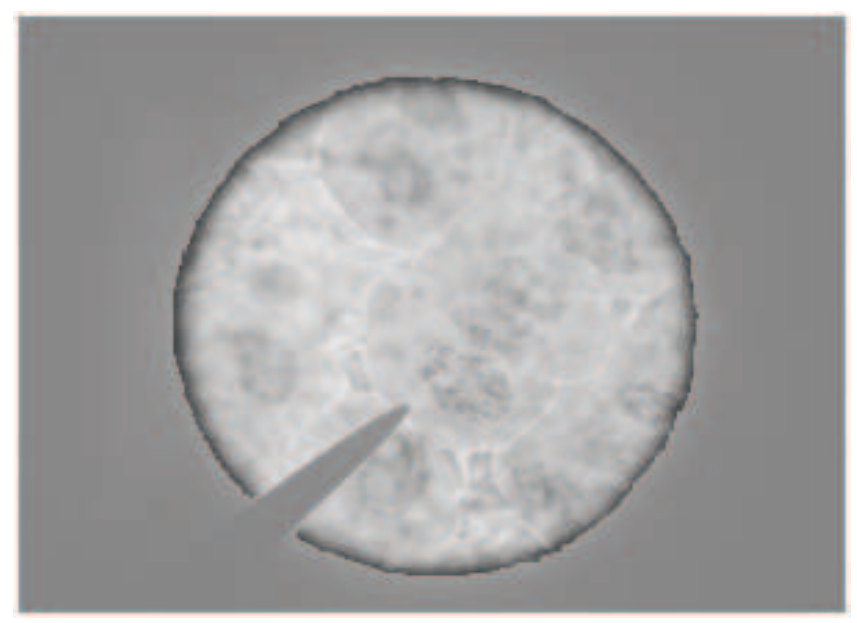

Figura 2: Célula metafase temprana, donde se observan los cromosomas. Con el objetivo de 100X.

\section{DISCUSIÓN}

El porcentaje de división celular o IM total (97.16\%) puede explicarse a que las plantas utilizadas eran muy jóvenes, por lo tanto su porcentaje de crecimiento era muy alto respecto a la planta adulta, pues según Izco (2004), la guadua pertenece a la familia de las gramíneas lo que quiere decir que estas hacen parte de las plantas con fotosíntesis tipo C4, que se caracterizan por presentar una saturación de luz entre los 200-300 J, transpirar entre 500-700g de agua por cada gramo de materia seca, que para Izco.,. , es otra razón por la cual esta planta presenta un ciclo mitótico tan activo, también se ha reportado que la guadua es una eficiente captadora de $\mathrm{CO}_{2}$, generando una gran cantidad de biomasa en corto tiempo (Judziewicz et al.,., 1999) lo que indica que constantemente se encuentra en crecimiento, es decir con un número alto de células en división. Según los reportes de Valencia., (2010), la especie se caracteriza por ser de rápido crecimiento y de colonizadora exitosa en los ecosistemas húmedos asociados a fuentes hídricas, por su propagación vegetativa eficiente, por lo que es de esperarse que posea adaptaciones de este tipo.

De la misma manera una explicación para la duración del ciclo celular ( 4.03 horas) y la presencia en la curva de varios picos durante las 24 horas del día (figura 1), consiste en que la guadua tiene alta productividad primaria neta lo cual es observable en su reproducción por rizoma, la espesura del follaje y el rápido crecimiento, lo que requiere una gran cantidad de división por mitosis para darle las características ya nombradas que es al fin una gran cantidad de biomasa; Valencia (2010), también encuentra una duración del ciclo celular cercano a 4 horas sin embargo con respecto a lo encontrado por Talledo \& Escobar (1995) este es un valor bajo para la especie.

El porcentaje del IF total de las profases de $41.42 \%$ (tabla 1), puede explicarse con el alto porcentaje de división (97.16\%) que presentó durante el ciclo celular, pues por este motivo es necesario que una cantidad considerable de células entren en profase para continuar dividiéndose, de igual forma se sustenta que la duración en horas de células en profase sea de 1.72, el cual es el más prolongado entre todas las fases. Una explicación para el bajo porcentaje de IF total de anafases (3.83\%) es la corta duración en horas del día de esta fase la cual es 0.16 horas, en 24 horas; de acuerdo con los resultados obtenidos por Valencia.,( 
2010), para G. angustifolia, el proceso mitótico inicia con división profase; congruente al incremento encontrado en el número de células en metafase; los procesos de metafase y anafase no requieren más energía que los anteriores dado que los dos estadios de división celular se realizan durante el tiempo óptimo de viabilidad energética del día (Halaban, 1972), además el índice mitótico de $G$. angustifolia muestra un crecimiento en el número de células que se encuentran en el estadío de mitosis, relacionado con el fotoperiodo, ya que este varío a través de las 24 horas del día mostrando altibajos, lo que indicó que la división celular para $G$. angustifolia está influenciada por los ciclos de luz y oscuridad (Halaban, 1972).

Es importante resaltar que las horas obtenidas de los picos más elevados en la curva de IM parcial (8:30, $15: 30$ y 16:30), son los momentos adecuados para realizar fijaciones con el objetivo de continuar con el procesamiento citogenético como el conteo y bandeo cromosómico y la elaboración del cariotipo, esto concuerda con lo expuesto por Ekamen \& Osuji (2006), en cuanto los niveles de mitosis tienen un punto máximo cuando se presentan altos niveles de luz solar, lo que indica que estos procesos demandan un requerimiento alto energético; Además el ciclo mitótico es de gran utilidad para realizar procesos de poliploidización inducida, a partir de la cual se obtienen plantas con características deseadas para la economía como el gigantismo (Cubero, J.I.,2003). Una buena manera de inducir la poliploidización es el uso de agentes poliploidizantes como la colchicina, la cual es de gran efectividad para conseguir nuevas variedades o genotipos pre mejorados en especies de interés económico (Escandón et al., 2006 y 2005; Hagiwara et al., 2002).

Con respecto al tamaño de los cromosomas (figura 2) Izco., (2004) plantea que no tiene mucha importancia taxonómica, pero evolutivamente se estima que las plantas con cromosomas grandes son más primitivas que las de cromosomas pequeños. Esto podría llegar a explicar el por qué la guadua tiene tal fácil adaptabilidad a diferentes condiciones climática y edáficas.

La importancia de este estudio es ante todo de tipo económico, ya que la citogenética es un área de la genética que se caracteriza por sus bajos costos, reproducibilidad, calidad de la información obtenida y que tiene la propiedad de permitir un acercamiento a potenciales programas de conservación y mejoramiento. Además la estandarización de técnicas y protocolos que permitan la obtención de células metafásicas, las cuales proporcionan material genético en condiciones apropiadas (cantidad, calidad), es muy importante en los estudios genéticos ya que de estos protocolos depende la calidad y profundidad de los estudios que se realicen.

Además con la ayuda de resultados como los encontrados en este estudio se podrían plantear elementos que esclarezcan la clasificación taxonómica de esta especie, lo cual es crucial en la identificación de las diferentes variedades de $G$. angustifolia, las cuales presentan características diferentes de uso económico como la calidad, resistencia y tamaño adecuado para diferentes actividades industriales, estos resultados también son de mucha significancia en estudios dirigidos a la biotecnología como generación de líneas mejoradas en términos de rendimiento y no sólo características maderables.

\section{CONCLUSIONES Y RECOMENDACIONES}

La G. angustifolia var. grandicaula tiene un alto porcentaje de división celular, lo cual la hace eficiente a la hora de colonizar espacios por medio de reproducción por rizoma.

La duración total del ciclo celular de la G. angustifolia var. grandicaula tiene un valor bajo pero constante a lo largo del día lo que se refleja en su capacidad de producir biomasa y tener así un rápido crecimiento.

Es recomendable la realización de nuevos estudios con respecto a la acumulación de agua en la parte basal de la planta en las horas de la madrugada, razón por la que se cosecha cerca de las 5:00 horas.

Se recomienda para otras investigaciones en citogenética de la especie realizar los cortes y las fijaciones a las horas 8:30, 15:30 y 16:30 puesto que a estas horas se hallan los picos más elevados de división mitótica.

\section{AGRADECIMIENTOS}

Los autores agradecen a la profesora Nohra Rodríguez y Jenny Valencia por sus asesorías continuas a través de la investigación, también al laboratorio de biotecnología por brindarnos material de trabajo $y$ espacio en el invernadero. 


\section{BIBLIOGRAFÍA}

Cubero, J. Introducción a la mejora genética vegetal. 2ª edición. Ed. Mundi-Prensa 2003. ISBN: 84-8476-099-5.

Ekamen, A., Osuji, J. Mitotic index studies on edible cocoyams (xanthosoma and colocasia spp). African journal of biotechnology 2006. 5(10): 846-849.

Escandón, A., Miyajima, I., Alderete, M., Hagiwara, J., Facciuto, G., Mata, D., Soto, S. Wild ornamental germplasm exploration and domestication based on biotechnological approaches. In vitro colchicine treatment to obtain a new cultivar of Scoparia montevidiensis. EJB 2005: Vol. 8, No. 2, p. 204-211.

Escandón, A., Miyajima, I., Alderete, M., Hagiwara, J., Facciuto, G., Mata, D., Soto, S. New variety of Bacopa monneri obtaind by in vitro polyploidization. En: Proceeding of VI Simposium REDBIO-Argentina. A Biotechnology vision from South America, 2006.

Giraldo, E., Sabogaln A. Una alternativa sostenible: La Guadua. 2 ed. Colombia: editorial Corporación autónoma regional del Quindío C.R.Q.; 2005.

Hagiwara, J., Hagiwara, J., Kato, A., García, L., Mori, M., Greppi, J. Obtención de poliploides en Calibracoa pygmaea mediante el uso de colchicina in vitro. En: 1er.Congreso Argentino de Floricultura y Plantas Ornamentales y 4 tas. Jornadas Nacionales de Floricultura 2002. Bs.As. p.90.

Halaban, R. Mitotic index and cell cycle of Lemma perpusilla under different photoperiods. Plant physiology, 1972. 50:308-310.

Izco J. Botanica.2 ed. Madrid: editorial McGraw-Hill interamericana 2004.

Judziewicz, E., Clark, L., Londoño, X., Stern, M. Américan bamboos. Washington: Editorial Smithsonia Institution, 1999.

Leegood, R. Carbon Dioxide Concentrating Mechanisms. P.J. Lea and R.C. Leegood (Eds.). Plant Biochemistry and Molecular Biology, 1993.

Murashige, T., Skoog, F. Revised medium for rapid growth and bio assay with tobacco tissue culture. Physiologia Plantarum. 1962; 15: 473 - 497.

Murray, W \& Nabor ,S. Introducción a la Botánica. Madrid: editorial Pearson Addison Wesley.; 2006.

Palomino, G., Martínez, J., Méndez, I. Citotipos en agave angustifolia haw. Determinados por citometría de flujo y análisis de sus cariotipos. Rev. Int. Contam. Ambient. 21 (Supl. 1) 4954, 2005.

Talledo, D., Escobar, C. El ciclo celular en vegetales. Su estudio, importancia y aplicaciones. Biotempo. 1995; 2:1331.

Talledo, D., Escobar, V., Alleman, X. Introducción al análisis cromosómico en vegetales. Lima, Universidad Ricardo Palma 1993.141 p.

Valencia, J. Caracterización citogenética de G. angustifolia Kunth var. angustifolia (Bambusoideae, Poaceae) A Partir De Tejido Radicular. Trabajo de grado (biología con énfasis en biodiversidad). Universidad del Quindío. 2010. 